\title{
Women in Higher Education: The Challenge Remains, Who Wears the "Pants"
}

\author{
Lisa Barnes ${ }^{1, *}$, Maria Northcote ${ }^{1}$, Carolyn Rickett ${ }^{1}$, Lynette Lounsbury ${ }^{1}$, Lily A. Arasaratnam-Smith ${ }^{2}$, \\ Kira-Leigh Josey ${ }^{1}$, Noelle Obers ${ }^{3}$ \\ ${ }^{1}$ Faculty of Education, Business and Science, Avondale Business School, Avondale University College, Cooranbong, NSW, Australia \\ ${ }^{2}$ Faculty of Business, Arts, Social Sciences and Education, Alphacrucis College, Parramatta NSW, Australia \\ ${ }^{3}$ Faculty of Commerce, Rhodes University, Grahamstown, South Africa
}

Received August 17, 2020; Revised October 24, 2020; Accepted November 1, 2020

\section{Cite This Paper in the following Citation Styles}

(a): [1] Lisa Barnes, Maria Northcote, Carolyn Rickett, Lynette Lounsbury, Lily A. Arasaratnam-Smith, Kira-Leigh Josey, Noelle Obers , "Women in Higher Education: The Challenge Remains, Who Wears the 'Pants'," Universal Journal of Educational Research, Vol. 8, No. 12, pp. 6885 - 6892, 2020. DOI: 10.13189/ujer.2020.081254.

(b): Lisa Barnes, Maria Northcote, Carolyn Rickett, Lynette Lounsbury, Lily A. Arasaratnam-Smith, Kira-Leigh Josey, Noelle Obers (2020). Women in Higher Education: The Challenge Remains, Who Wears the "Pants". Universal Journal of Educational Research, 8(12), 6885 - 6892. DOI: 10.13189/ujer.2020.081254.

Copyright $\bigcirc 2020$ by authors, all rights reserved. Authors agree that this article remains permanently open access under the terms of the Creative Commons Attribution License 4.0 International License

\begin{abstract}
This research was initially done across disciplines and across faculties in one faith-based higher education institution in Australia, to discover the challenges and opportunities faced by women in the higher education sector. It was then expanded to see if these issues were different for those working in secular institutions, as well as other faith-based institutions. A replicated study, it also compares results to a study completed at Rhodes University in South Africa. The results were similar across all institutions. Women are still facing three major issues in the higher education sector: namely, lack of self-esteem, attempting (unsuccessfully) to create life/work balance, and continued hurdles presented by stereotypical gender roles. The present research adds to that of the past by confirming that there are still workplace barriers in place; however, there is a positive view that unconscious biases are changing, and that no longer are lifelong careers only reserved for males in higher education. Although workplace experiences for women are changing, it is proposed that a future vision for women in the higher education workforce should contain formal and informal mentoring as well as role modelling and use of Women's groups to support and promote women in higher education, thus creating a greater convergence of gender opportunities.
\end{abstract}

Keywords Unconscious Bias, Life/Work Balance,
Self-esteem, Women in Higher Education

\section{Introduction}

THE present study is a replication of research that was initially done in South Africa at Rhodes University, a secular higher education institution, to study the challenges and barriers women face when attempting to forge a successful career in academia. The results of this study indicated that the top three barriers were family responsibilities with traditional gender roles and gender bias, the challenges of balancing life and work responsibilities, and low self-esteem and confidence. [1]. Enablements included access to information, conferences, as well as opportunities to mentor and be part of professional networks. The present project used the results of the initial study and applied them to two Australian faith-based higher education providers. Participants included professional and other female staff in addition to teaching faculty, a divergence from the initial study, to see if the results would differ. Surprisingly, the top three challenges remained the same; but staff were optimistic that these challenges were being addressed, and were hopeful of the future for women in higher education career pathways. 


\section{Literature Review}

The nature of academic work can be generally categorised into teaching, research, and administration. Various institutions have different percentages attached to each of these types of work (e.g. $40 \%$ teaching, $40 \%$ research, $20 \%$ administration) [2], but inherent is the need to research. However, for females in particular this expectation of research output is challenging, as illustrated by the 2017 National Research Census [3] which notes that only $25 \%$ of research completed in Australia is done by females. The other challenge is career promotion. According to Universities Australia [4], female staff members in the early stages of their career make up to $45 \%$ of overall academic staff in 2016. However, this decreases to $27.3 \%$ at the senior academic level (Level D and above). It is evident in research that greater representation of women in workplaces offers tangible benefits such as increased performance of the organisation, and can create organic change and diversity of institutions [5]. Universities Australia has set up the "Universities Australia Executive Women's Group" [6] in order to address these shortfalls and encourage more female representation, even publishing "Guidelines for addressing unconscious bias” [7] to establish best practice in the recruitment, retention and promotion of women in academia.

The issue of gender inequity is not a new concept, particularly regarding positions of power [8]. Gender equity challenges in higher education leadership positions have been widely discussed [9] \& [10]. Higher education providers have certainly been changing their policies to encourage staff to be more inclusive. However, the majority of leadership positions remain occupied by men [12]. Globally, men occupy $70 \%$ of research positions in higher education [13], and produce more research than women [4].

The research reported in this paper uses a replicated study to survey and interview women in faith-based institutions to examine whether they identify the same or similar challenges and opportunities identified in previous research.

\section{Methodology}

The aim of this project is to identify the current constraints and facilitators that women face in higher education institutions. It is hoped that this research will increase the participation of women in higher education institutions, increase research output of female academics, and facilitate succession planning and career progression for women in academia. Specifically, the present study engages with the following research questions:

1) What are the challenges women in academia (faculty and general staff) experience due to family responsibilities and hegemonic power relations in the institution?

2) How do supportive structures facilitate or impede advancement for women?

A mixed methods multiphase design was the guiding methodological approach to the investigation [14]. Within this design, individual phases consisting of both quantitative and qualitative data collection, analysis and interpretation were conducted in each phase. An online survey was administered, to gather information on the current status quo in relation to current constraints and enablements for women working in faith-based higher education. Twelve individual interviews were also undertaken with a selection of the participants of the study to gain in-depth knowledge, participants were from both academia and administration within the higher education institution. The long-term goal of the project is to provide empirically-based evidence to inform the development of future staff mentoring activities that best suit the needs of female staff in higher education institutions.

\section{Results}

The initial results of the survey indicated that female staff members noted that the top three challenges for career development in academia were as follows: 59\% of respondents stated that conflict with traditional gender roles (career vs parenthood) was the biggest factor in career development, followed by $40 \%$ family responsiblities and $35 \%$ self esteem(see figure 1). 


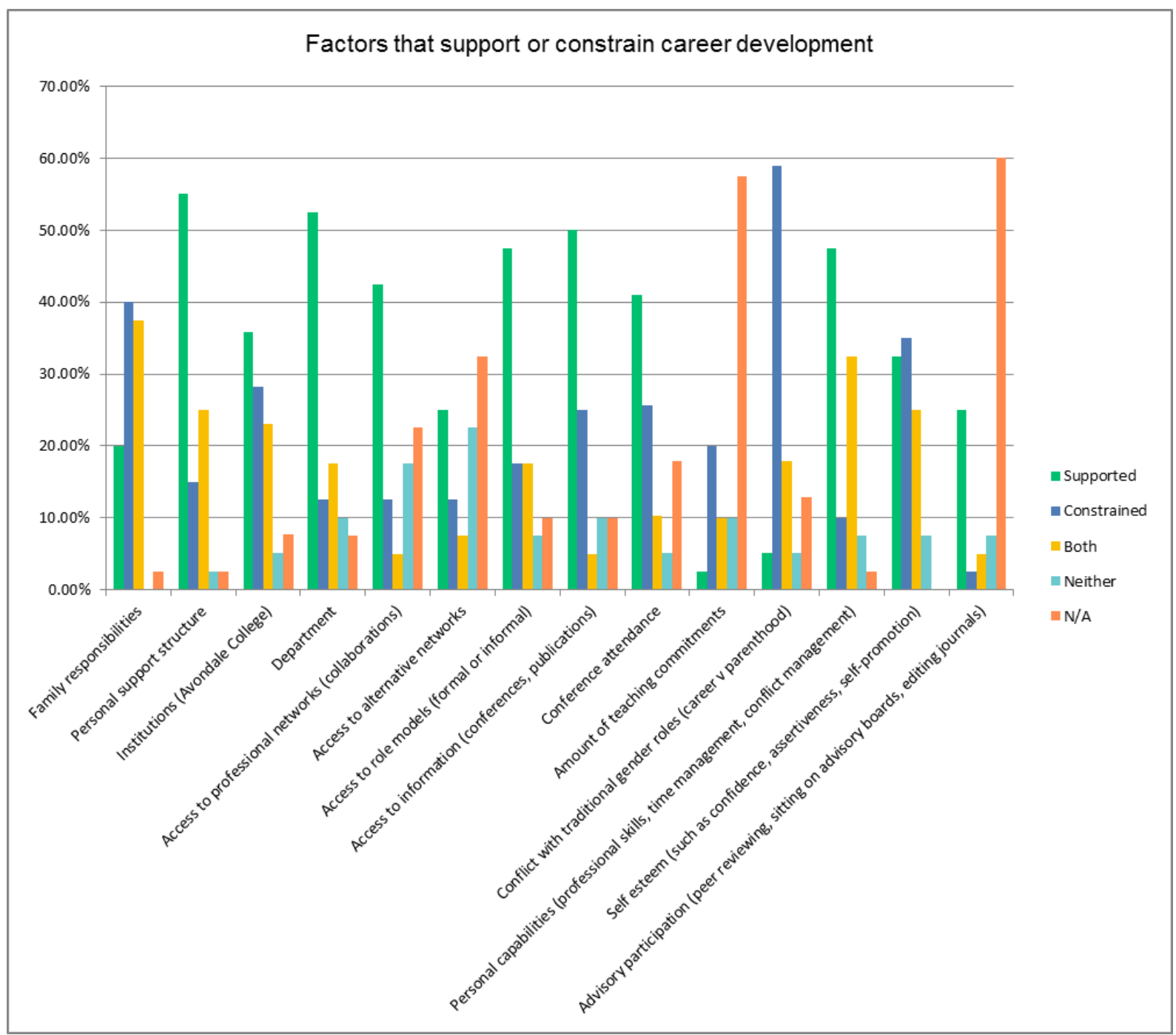

Figure 1. Constraints

Figure one shows that participants felt that these issues either a) supported them in their role, b) constrained them in performance of their role, or c) did both at the same time, or d) did neither support or constrain them.

These results were then compared to the initial results from Rhodes University as follows in table 1 :

Table 1. Comparison of Top 3 Challenges

\begin{tabular}{|c|c|c|}
\hline Challenges & $\begin{array}{c}\text { Faith-based } \\
\text { Institutions }\end{array}$ & Rhodes University \\
\hline $\begin{array}{c}\text { Conflict with traditional } \\
\text { gender roles }\end{array}$ & $59 \% 1^{\text {st }}$ & $65 \% 1^{\text {st }}$ \\
\hline Family Responsibilities & $40 \% 2^{\text {nd }}$ & $60 \% 2^{\text {nd }}$ \\
\hline Self Esteem & $35 \% 3$ rd & $46 \% 3^{\text {rd }}$ \\
\hline
\end{tabular}

Challenge 1: Conflict of gender roles.

Women in this study generally indicated that they find gender roles constrain their career development. Lester [15] proposes that 'within performativity, individuals have the agency to choose to perform gender in any way that they desire, but they must navigate gender norms that are contextually and culturally defined' (p. 161). Quotes from participants indicate the ongoing challenge still exists:

"The difficulty of balancing your family responsibilities, recreation, church involvement and work is, I believe something that most women struggle with and don't know of many who are happy with the balance they have achieved. We are however, our own worst critics though!!”

"Family commitments, over the years, have had a huge constraining effect on my career. Not that I regret the decisions and choices I have made, but this is simply stating the realities of life for me".

"In the past I have notice males being offered opportunities to attend conferences and given more opportunities to network than females.”

Challenge 2: Family Responsibilities.

The finding that family responsibilities constrain career development is supported by the McKinsey \& Company study which found that women experience the "double 
burden” syndrome of having to balance work and domestic responsibilities as an obstacle, [16]. Quotes on this challenge, offered by the participants in our study, are as follows:

"Yeah, I do feel like - this is double-edged sword. I think if you have kids, you're a bit disparaged as an academic but then I think if you don't have them, as a woman, you get piled on with all things you should be able to do.”

"Look, when my kid is in trouble. That's more important than anything."

"The whole work and family balance can be very challenging at times. I am content with where I am at with my career but believe I would have gone further by now had I not also been a parent”.

"Being a single parent it is at times difficult to balance my family commitments with my work commitments. Although family comes first, I tend to feel guilty if I have to leave work to attend to my children's needs (eg sickness)"

"As a woman, family is one thing that cannot be ignored. I choose to spend quality and quantity of time with my family. This has impacted on the time I have spent on research.”

Challenge 3: Self-esteem.

The McKinsey \& Company study also found that women had this "anytime, anywhere" performance model [16] and that women are constrained by their self-esteem, and their inability to promote themselves [16], as confirmed by the following:

"My self-esteem is my biggest constraint...I really need to work on my 'imposter syndrome!'”

“... if I do these other things, it will just block me from going forward with my research or research leadership or research training"

"Because of my gender I feel I have an advantage in being able to network really well, ask for support when I need it, access alternative networks that I need at a particular point in my life, etc."

"No matter how hard you try, you are perceived as inferior to a man"

"Often I feel shut out and and driven by a task base management approach instead of a collaborative, creative and growth mindset. (I am feeling so sad right now having to answer this question)"
"I hope nobody finds out the fraud I am. I hope they don't find out what a fraud I am, that I'm not as good as everybody says I am”

"Oh god, I'm hopeless. I really felt devalued and minimised and "What a waste of time," I thought."

Issue 4: Supportive Structures: Women's Networks

Due to the high results of support indicated for professional networks and access to role model, a search was undertaken to find out what institutions in Australia have specific networks for women in higher education as shown in Table 2. Both the faith-based organisations had only recently set up their networks, and specifically targeted other successful female academics to speak to the group and to encourage a mentoring model within the institution.

Table 2. Women's Groups in Higher Education

\begin{tabular}{|c|c|}
\hline University/ Institution & $\begin{array}{l}\text { Name of network, program, } \\
\text { group }\end{array}$ \\
\hline Alphacrucis College & Women Faculty Group \\
\hline Australian Catholic University & Leadership for Mission \\
\hline Avondale University College & Avondale Women's Network \\
\hline $\begin{array}{l}\text { Queensland University of } \\
\text { Technology }\end{array}$ & $\begin{array}{l}\text { Graduate School of Business } \\
\text { Women in Leadership } \\
\text { Excellence Scholarship }\end{array}$ \\
\hline Universities Australia & Executive Women's Group \\
\hline University of Adelaide & $\begin{array}{l}\text { Adelaide Women Leadership } \\
\text { Development Program }\end{array}$ \\
\hline $\begin{array}{l}\text { University of New South } \\
\text { Wales }\end{array}$ & Women in Leadership Course \\
\hline $\begin{array}{l}\text { University of New South } \\
\text { Wales }\end{array}$ & $\begin{array}{l}\text { Women in Leadership Research } \\
\text { Network }\end{array}$ \\
\hline University of Queensland & $\begin{array}{l}\text { Leadership for Executive } \\
\text { Women course }\end{array}$ \\
\hline University of Sydney & $\begin{array}{l}\text { Women, Work and Leadership } \\
\text { Research Group }\end{array}$ \\
\hline University of Sydney & Women in Leadership Course \\
\hline University of Newcastle & $\begin{array}{l}\text { Newcastle University's Women } \\
\text { in Engineering }\end{array}$ \\
\hline University of Newcastle & Women in Innovation \\
\hline University of Newcastle & Women in Leadership \\
\hline University of Newcastle & $\begin{array}{l}\text { Women in Master of Business } \\
\text { Administration (WiMBA) } \\
\text { Scholarship }\end{array}$ \\
\hline
\end{tabular}

One of the faith-based institutions had kept a record of the number of meetings, speakers and research to report to the institution of the success of the group as shown in figure 2. This demonstrate regular meetings, influential speakers from both academia and administration, as well as research projects initiated and grants applied for. 


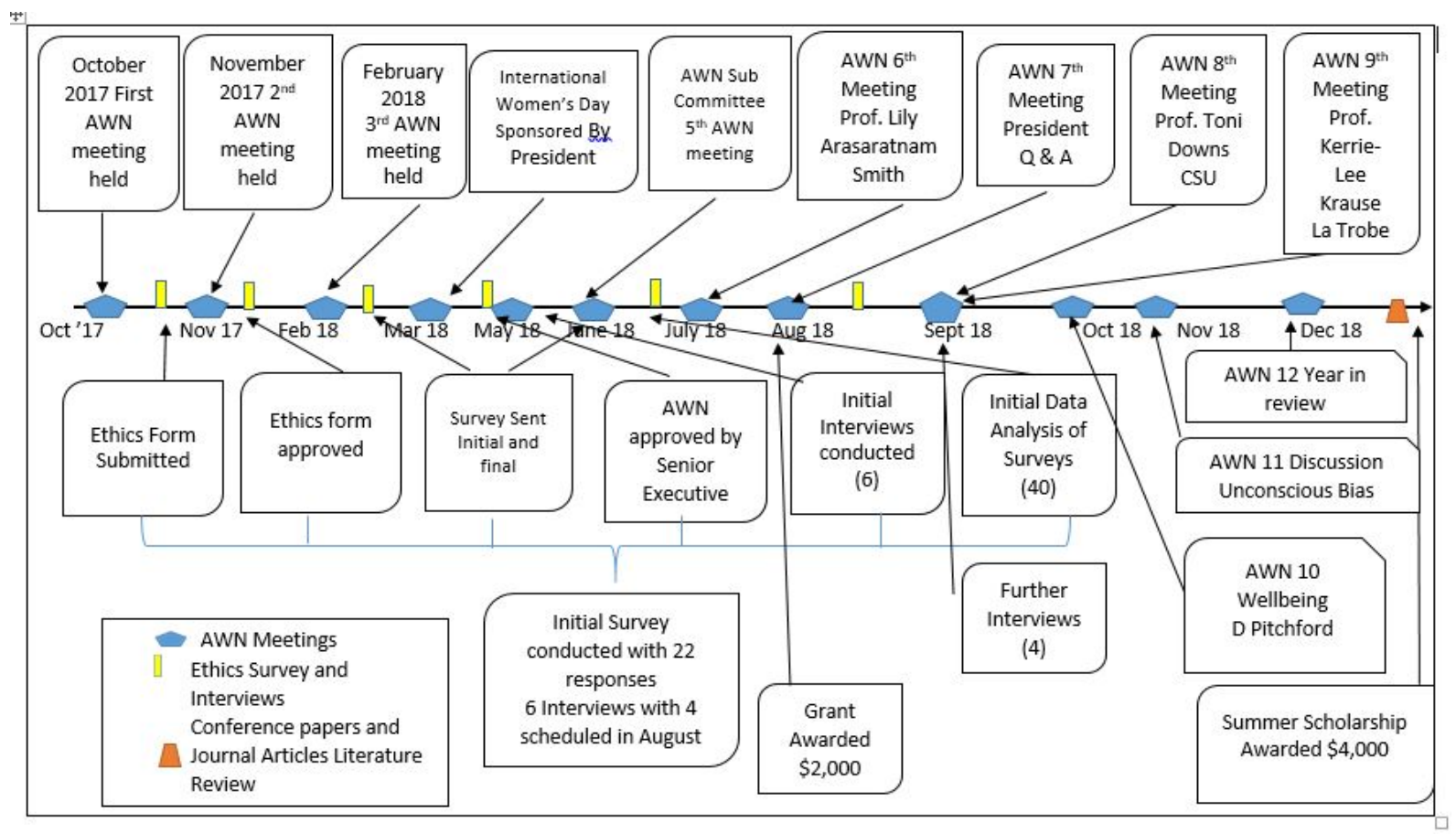

Figure 2. Women's Group Annual Timeline

Developing networks has been evidenced to be an essential strategy for career advancement, personal satisfaction, and growth [19]. Worker support is crucial as it increases morale in staff [20].

Events completed within other women's networks include reflection, network maps and one-on-one mentoring [21]. The Higher Education Resource Services (HERS) Institute employs a curriculum for advancing female leaders in education, which includes giving out assignments. Most women's groups are concerned with advancing women towards promotions and not building relationships.

Part of the feedback given on the use of women's groups from the participants in our study are as follows:

"I'm really excited about it because I think that women need a lot of support in many areas."

“The fact that we're getting men presenters coming in I think is wonderful."

"Women's Network is critical for the college and for the church, and I think that being a higher ed institution on the brink of being a university, needs to show leadership and that leadership can come through the network through the scholarship and that we have a duty and a responsibility for this generational change, and this is a responsibility we owe to- not just the church, but to our students."

"I think everyone is going to realise we were on the same team.”

"empowerment around who do you want to hear from and why to be able to choose the messaging. I mean, that's incredibly powerful of what the agenda items are being set. Incredibly powerful to see those trust mechanisms start to be building over time."

"valued and for them to be told on an institutional level that they are okay"

"We had 36. There are only 84 women working here, that's almost half physically attended that meeting”

“It's really good. So for me, it's made my job easier because I now have a network of people that are helping me.”

"I can now walk around the camps and say hello to a lot more other women.”

\section{Issue 5: Supportive Structures: Mentoring}

Mentor role theory states that mentoring has two functions: [17] firstly, to provide support at a career or vocation level, in the way of sponsorship, coaching, protection, exposure and challenging assignments; and secondly, to provide support at a psycho-social level by providing acceptance, confidence, counselling, friendship, and role modelling [18]. Opinions on mentoring are as follows:

“Always put me forward when a job came up. Always. He's got me first”

“Conversations which I've had with people to brainstorm or to run through ideas off and on. But in terms of mentoring, not really. Nothing.”

“I wouldn't say anything where I have never felt supported which has been really great. I always have. I have a really good buy-in from people. I surrounded myself with really positive people as well” 
“... they [other group members] made me realise that I have skills that I didn't necessarily know I had”

"He's- and I went back for that because this man really stepped in as my father figure and really shaped my ambition and always checked on me and made sure"

“... she was just so competent. And so, I gave her more and more authority....I think that's just so important to... affirm and encourage people so they realise they're of value”

"I had official mentor at my first job which is that lady I mentioned who was quite cold and distant but valuable so she was alright”

\section{Discussion on Thematic Map}

The thematic map (Figure 3) highlights the major themes which emerged from an analysis of interview data from professional and academic women at two tertiary institutions. The interview data was coded using a qualitative data analysis program (NVivo). The major themes which emerged from the study were identified as 'Career', 'Mentoring', 'Personal life and values', and 'Experiences in the Workplace'. The findings from an analysis of the interview data was translated into the thematic map, illustrated in Figure 3. The six significant themes are positioned centrally to the research title 'The Experiences of Women in Higher Education'. The six highlighted issues are each surrounded by sub-themes. All the themes are colour-coded according to the number of interview comments that formed each node. If a node had a high number of comments, this indicates that the theme was mentioned several times by several interviewees signalling the relative importance of the topic. The key to the colour coding of the nodes is located in the bottom left of the map. Some themes have small 'red' and 'blue' flames situated next to them. These flames indicate high emotional intensity and high emotional involvement/ investment, respectively. 'Killer' or highlight quotes were compiled from the interviews. These quotes were chosen because they were well-phrased and embodied the general sentiment of the theme, and were particularly representative of the themes that emerged from analysis of the interview data. These quotes are positioned around the thematic map close to the topic they are related to.

When commenting on mentoring, many women shared that they felt supported and that mentors helped them to grow by encouraging skills that they did not know they had. Despite the comments about mentors assisting individuals to be resilient or put forth for promotion, women also highlighted situations where they had had negative experiences with mentoring. Interviewees highlighted that some mentors had a constant idea of being in a deficit and actively aimed to pull others down.

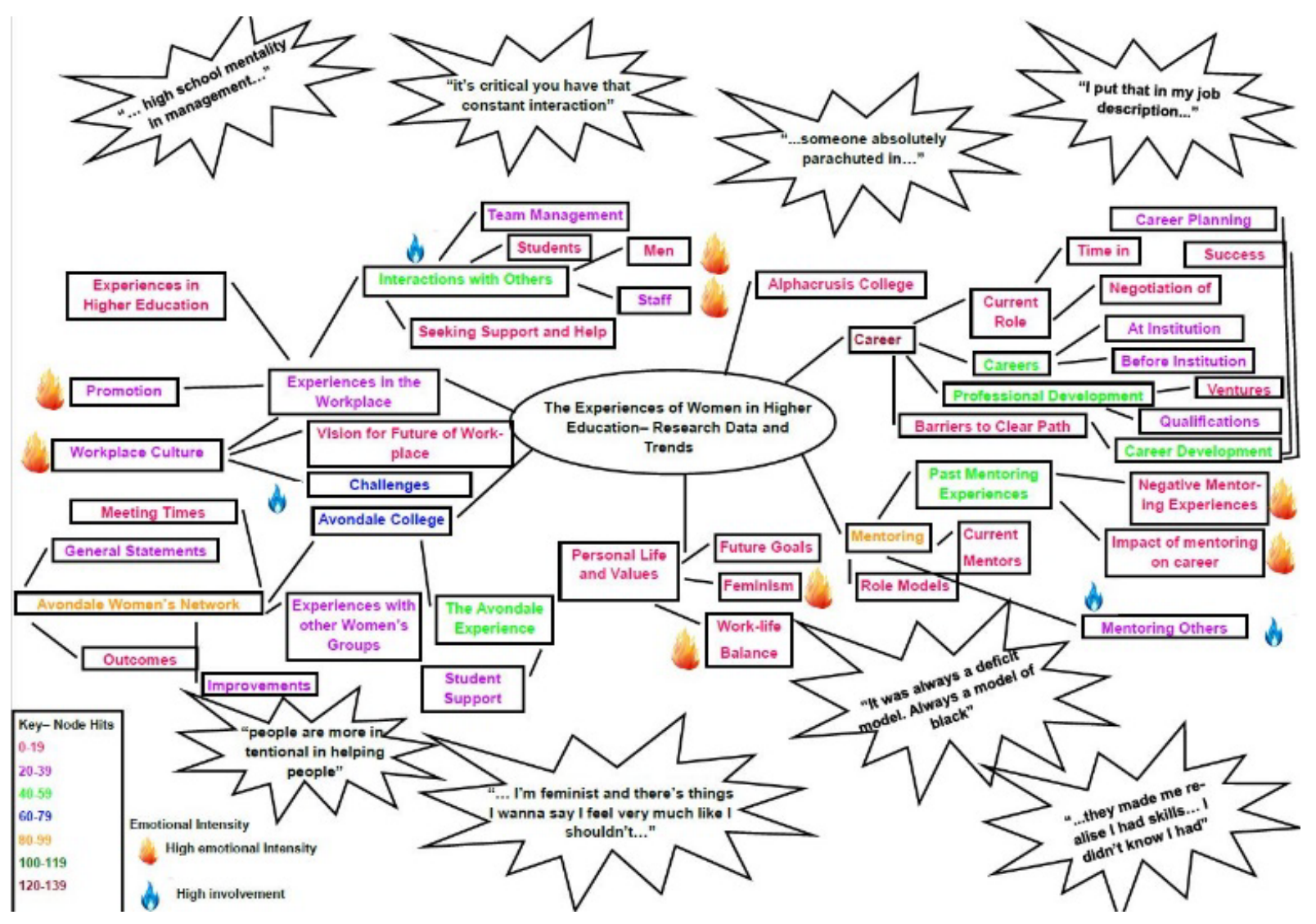

Figure 3. Thematic Map 
Many people mentioned that they had a positive experience in a faith-based organisation. Most noted that they felt support from their peers as they thought others intentionally sought to help them. Some women talked about how they got less pay then male staff and most faced an initial struggle in adjusting to the College. The community focus of the College was also highlighted; many women interviewed bought up their positive feelings towards the students and female staff in the early stages of their career, and expressed a desire to mentor both them. The Women's Network was universally seen as positive, despite mentions of suspicions and reservations some people may have around women's groups. Interviewees noted that the network was an essential step for the College and that it has the potential to be a powerful vector for change. The interviewees typically attended the group regularly, and if they had missed the meetings, they had a valid reason. Suggestions to improve the group included developing a code of conduct and conducting training and leisure activities together.

When women in this study discussed their 'clear path' many mentioned that they had in their mind what they thought their clear path was but that this did not manifest. Some women said that their career path chose them and that the development of their career was entirely accidental. Although some women struggled to progress through their careers, others noted that they had help from others and, as a result, were promoted more efficiently. The interviewees mentioned that they had an essential role in negotiating their job description while others were not ever, and still are not clear, in their position.

Professionally, women noted that they had to consistently work towards getting new qualifications as at times they did not have the exact requirements for their role. Women also expressed a desire to receive more training but mentioned that gaining time and permission for this was difficult. When speaking about promotion, some noted that they had been very actively promoted while others had been denied a promotion (often wrongfully, as claimed by some participants) and had their confidence shaken. Women also noted times where they had seen men "parachute" into a role for which they were not as qualified as some of their female colleagues.

Women had varied experiences in the workplace. Where some noted that they had seen workplace culture stagnate and that change was a struggle to instigate, others observed that they had seen their workplace culture change for the better. The impact of negative workplace culture on staff was also referred to as an isolating force. Some mentioned that when those in positions of leadership did not work well with the team, the entire group's work was impeded. Challenges are also rampant in the workplace with interviewees mentioning that they felt as though their work went unnoticed and that their hard work often went unnoticed. Women also noticed that it appeared that some men resented their success in the workforce, but others mentioned men who had actively put them forward for promotion. The importance of managing teams properly was also discussed with the values of accountability and transparency emphasised.

Women also referenced their personal lives with some mentioning that they felt that the achievements of women deserve to be recognised and that they had feminist values. Intentionality was mentioned regarding women's future work-related and personal goals with women noting that they needed to capitalise on their opportunities and make their choices carefully. Work-life balance was also mentioned as a struggle, with many noting that although their careers were often flexible, it was a struggle to balance looking after both their career and families.

\section{Conclusions}

The present study examined the following research questions:

1) What are the challenges women academics and general staff experience due to family responsibilities and hegemonic power relations in the institution?

2) How supportive structures may or may not facilitate advancement for women?

Overall, the results confirm that the top three challenges that women are still facing in the higher education sector are the conflict of traditional roles, family responsibilities, and a lack of self-esteem. However, many participants in the study noted supportive structures within the institution, such as women's networks and mentoring. With the advent of Universities Australia Executive Women's Group supporting other higher education institutions in formalising and running groups, women should be further supported for satisfying careers in higher education in the future. Recommendations include formalization of Women's Groups to increase further participation in the higher education sector, and a mentoring program to help early career higher education participants to increase career progression and pathways. It is hoped this study will be again replicated in other higher education institutions to further promote policy change and create more opportunities in the sector for women in the future. One final quote sums up the general feelings of life/work balance with a family and career in academia:

"Every working woman needs a wife at home!"

\section{REFERENCES}

[1] Obers, N. "A Case Study of the Research Careers of Women Academics: Constraints \& Enablements" Masters of Education Thesis, Rhodes University, 2012.

[2] Vajoczki S., Fenton, N., Menard, K., \& Pollon, D.. 
Teaching-stream faculty in Ontario universities. Higher Education Quality Council of Ontario, Toronto, 2011.

[3] NCRIS National Research Infrastructure for Australia "National Research Infrastructure Census" Australian Government, 2017

[4] Universities Australia 2016 Selected Inter-institutional gender equity statistics 2016.

[5] Deloitte Access Economics "Research Report Toward Gender Parity: Women on Boards Initiative”, Department of Communities, Child Safety and Disability Services, Offices for Women, 2016.

[6] Universities Australia Executive Women's Group https://www.universitiesaustralia.edu.au/policy-submission s/diversity-equity/universities-australia-executive-womengroup/

[7] Universities Australia Executive Women's Group “Guidelines for addressing unconscious bias” 2017

[8] Slaughter, A. Why women still can't have it all. The Atlantic. July/August

2012.http://www.theatlantic.com/magazine/archive/2012/0 7/why-women-still-can-8217-

[9] White, K., Riordan, S., Özkanli, Ö., \& Neale, J. Cross culture perspective of gender and management in universities. South African Journal of Higher Education, 24 (4), 646-660 2010.

[10] Shackleton, L., Riordan, S., \& Simonis, D. Gender and the transformation agenda in South African higher education. Women's Studies International Forum, 29, 572-580 2006.

[11] Enke,A., “Transfeminist Perspectives In and Beyond Transgender \& Gender Studies” Temple University Press,
ISBN 1-4399-0747-4 2014

[12] UNESCO “Shaping the Education of Tomorrow” Report on the UN decade of Education for Sustainable Development UNESDOC Digital Library, 2012

[13] Creswell, J., \& Cresswell, J.D., "Research Design, Qualitative, Quantitative \& Mixed Method Approaches” 2018.

[14] Lester, J. Regulating gender performances: Power and gender norms in faculty work. NASPA. 142-169. http://journal 2011

[15] Desvaux, G., Devillard, S., \& Sancier-Sultan, S. Women at the top of corporations: Making it happen. Women Matter. McKinsey \& Company 2010.

[16] Kram, K. Improving the mentoring process. Training \& Develoment Journal, 39(4), 401985.

[17] Kram, K., \& Isabella, L). Mentoring alternatives: The role of peer relationships in career development. Academy of Management Journal, 28(1), 110-13 19852.

[18] Moazzam, Jabeen, Ansari and Salman "Mentoring, Networking and Politicking in Higher Education Institutions: A Gendered Perspective” 2015

[19] Lizano, E., Hsiao, H., Mor Barak, M., \& Casper, L. Support in the Workplace: Buffering the Deleterious Effects of Work-Family Conflict on Child Welfare Workers' Well-Being and Job Burnout. Journal of Social Service Research, 40(2), 178-188, 2014.

[20] Parker, Polly., Hewitt, Belinda., Witheriff, Jennifer and Cooper, Amy Frank and fearless: supporting academic career progression for women in an Australian program. Administrative Sciences 8 (1), 5, 2018. 